\title{
Design of a CPW-Fed Ultra Wide Band Antenna*
}

\author{
Shaowen Hu\#, Yiqiang Wu, Ye Zhang, Huilin Zhou \\ Department of Electronic Information Engineering, Nanchang University, Nanchang, China. \\ Email: "hsw5055613@126.com, yiqiangwu@126.com,806814726@qq.com,zhouhuilin@ncu.edu.cn
}

Received July $9^{\text {th }}, 2013$; revised August $30^{\text {th }}, 2013$; accepted September $9^{\text {th }}, 2013$

Copyright (C) 2013 Shaowen Hu et al. This is an open access article distributed under the Creative Commons Attribution License, which permits unrestricted use, distribution, and reproduction in any medium, provided the original work is properly cited.

\begin{abstract}
A CPW-fed ultra-wideband antenna was designed. The antenna was etched on a single-layer copper-cladding substrate, of which the material was FR4 with relative permittivity of 4.4, and the magnitude was $40.0 \mathrm{~mm} \times 50.0 \mathrm{~mm} \times 1.6 \mathrm{~mm}$. The parameters of the antenna are simulated and optimized with HFSS. This paper proposes a new trapezoidal CPW-fed UWB antenna that the bandwidth (return loss $\leq-10 \mathrm{~dB}$ ) covers 2.7 - $9.3 \mathrm{GHz}$ range, which means a relative bandwidth of $110 \%$ with good radiation patterns and gain. Simulated and measured results for return loss, radiation pattern and gain were presented. A good agreement has been obtained between the simulation and experiment and the proposed antenna meets the requirements of the ultra-wideband antenna.
\end{abstract}

Keywords: Ultra-Wideband (UWB) Antenna; Coplanar Waveguide (CPW); HFSS Simulation; Trapezoidal

\section{Introduction}

Traditional Ultra-wideband (UWB) antennas have been unable to combine with the modern integrated system for their complex structures and large volumes, miniaturized ultra-wideband printed antennas being good candidates for their low profile. Recently CPW-fed printed antennas have received considerable attention owing to their attractive merits, such as ultra-wide frequency band, good radiation properties and easy integration with system circuits.

However, most previously reported CPW-fed antenna designs are complex [1-4], with poor radiation patterns, unsuitable for practical applications. In this paper, a new tapered CPW-fed isosceles trapezoid disk printed monopole UWB antenna is proposed. A prototype antenna was fabricated and measured. It demonstrates that the compact design can achieve an ultra wide bandwidth, the operation bandwidth being $2.7-9.3 \mathrm{GHz}$, covering WLAN operating band, with satisfactory radiation patterns and $9.6 \mathrm{~dB}$ peak gain.

\section{Antenna Configuration and Analysis}

In order to achieve the broadband performance of the micro-strip antenna, some scholars have proposed a variety of antenna structures [5-7], such as U-slot patch antenna,

\footnotetext{
*Project supported by the National Science Funds of China (61062009).

${ }^{\#}$ Corresponding author.
}

bow-shaped antenna, monopole antenna, etc. [1].

The design of antenna used the symmetrical structure of coplanar waveguide bandwidth up from 3.5 to 11.0 $\mathrm{GHz}$ (VSWR < 2), but these antennas are large in size. The radiating patch generally used unit of area of regular shape, such as rectangular, circular or circular ring sheet micro-strip patch. With the same working frequency, the rectangular patch is available to slight higher efficiency, gain and wider bandwidth than the circular patch. The method of increasing the antenna bandwidth [2-4,8]: Multipatch, gap loading, lumped element loading (including short-circuit pin) and the feed point. These methods have advantages and disadvantages, such as multi-patches and lumped element loading will make the structure of the antenna complicated, doublyfed point resonant frequency tuning range is subject to certain restrictions, slotting may change the resonant frequency points. The impedance frequency characteristics of disc cone antenna are significantly superior to the ordinary dipole antenna. Based on the idea of applying planar printed structure to replace the traditional 3D disk cone antenna, the geometry structure of the proposed antenna is shown in Figure 1. Coplanar waveguide feed structure consists of the feed-forward signal band and the feed-forward signal with both sides of the slit. The magnitude of antenna was $40.0 \mathrm{~mm} \times 50.0 \mathrm{~mm} \times 1.6 \mathrm{~mm}$, of which the material was FR4 with relative permittivity of 4.4. The parameters of the antenna were simulated and optimized with HFSS, The result shows that the band- 
width is from 2.7 to $9.3 \mathrm{GHz}$ which means the compact design can achieve an ultra wide bandwidth, the operation bandwidth being $110 \%$.

\section{Analysis and Simulation}

To ensure the effectiveness and practicality of the designing, we must consider the dielectric substrate thickness and finite coplanar waveguide structure. The antenna feed structure is calculated in Equations (1)-(7).

$$
\begin{gathered}
z_{0}=\frac{30}{\sqrt{\varepsilon_{e f f}}} \frac{K\left(k_{0}^{\prime}\right)}{K\left(k_{0}\right)} \\
\varepsilon_{\text {eff }}=1+\frac{\varepsilon_{r}-1}{2} \frac{K\left(k_{1}\right) K\left(k_{0}^{\prime}\right)}{K\left(k_{1}^{\prime}\right) K\left(k_{0}\right)} \\
G=2 s+W \\
k_{0}=\frac{w}{G} \\
k_{0}^{\prime}=\sqrt{1-k_{0}^{2}} \\
k_{1}=\frac{s h(\pi w / 4 h)}{s h(\pi G / 4 h)} \\
k_{1}^{\prime}=\sqrt{1-k_{1}^{2}}
\end{gathered}
$$

In above equations $h, \varepsilon_{r}, \varepsilon_{\text {eff }}, w, s$ were the thickness of the dielectric substrate, the substrate relative permittivity, the effective dielectric constant substrate, the width of CPW-fed wire, the gap between CPW-fed wire and the ground. $K\left(k_{0}\right), K\left(k_{1}\right), K\left(k_{0}^{\prime}\right), K\left(k_{1}^{\prime}\right)$ are the first complete elliptic integral function its complement function. We can calculate the width $w$ and gap width $s$ of the CPW signal line by using the above formula.

It is convenient to match with the ground employing the tapered feed strip. In this study, $w$ and $s$ are respectively fixed at $2.6 \mathrm{~mm}$ and $0.28 \mathrm{~mm}$ while $\varepsilon_{r}=4.4, h=$ $1.6 \mathrm{~mm}$ in order to achieve $50 \Omega$ impedance.

A Lumped Port excitation will be used for the CPW

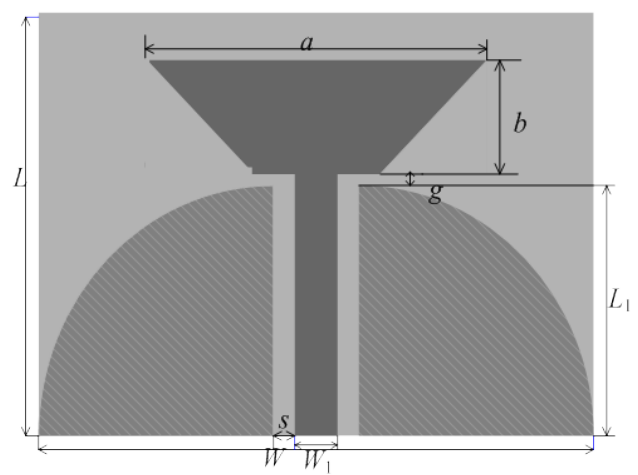

Figure 1. Structure of the antenna. feed. The simulation process and platform are as the following [9-12]:

Launching Ansoft HFSS13.0 and Create the model

Save Project;

Model Validation; Analyze

TO start the solution process; Solution Data

Create Reports; Far Field Overlays

Create Far Field Overlay

By scanning and optimizing of the parameters a, the effect that the radiation patch size has on the antenna impedance characteristics shows in Figure 2, the smaller radiation patch is, the less energy it emits. The bandwidth of the antenna is relatively small, with the increasing size of the radiation patch, the antenna impedance bandwidth has increased accordingly.

Seen from Figure 3, with the feed gap "g" between the patch and coplanar waveguide decreasing, the bandwidth of the antenna decreases, it is mainly because of the decrease of the gap that makes the coupling capacitance which between the antenna radiating patch and the coplanar waveguide ground changed, therefore, caused the antenna impedance bandwidth becoming narrowed.

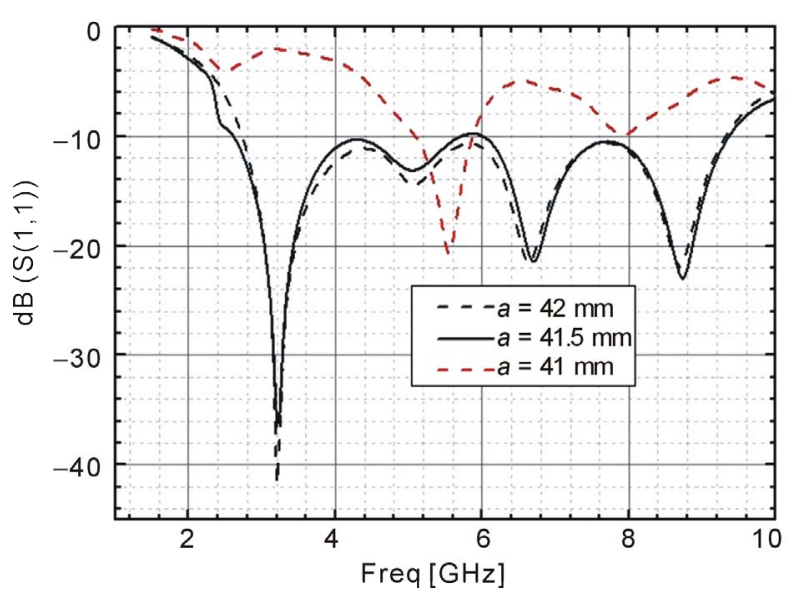

Figure 2. Effect of the patch on $S_{11}$.



Figure 3. The effect of the slot on $S_{11}$. 
While the antenna achieved the ultra-wideband performance, it has a good pattern and gain indicators. Figures 4(a) and (b) show the simulated radiation map of the antenna in 2.0, 5.0 and $10.0 \mathrm{GHz}$. H-plane pattern of the antenna in the low-frequency was Omni directional radiation in working band, radiation is strongest in the $\varphi=0$ and $\varphi=\pi$, the main lobe of the E plane pattern at $\theta=0$ and $\theta=\pi$; in a relatively high-frequency point of the main wave direction is slightly changed, the $\mathrm{H}$-surface radiation is zero at $\varphi=-\pi / 2$. Simulation gain, as Figure 5(c) shows in whole band from 2.7 to $9.3 \mathrm{GHz}$, the gain is greater than $3 \mathrm{~dB}$ the antenna gain has increased by the increasing of frequency. When the frequency is higher than $8 \mathrm{GHz}$, the antenna gain will in a relatively flat trend, top to $5.8 \mathrm{~dB}$, which is better than of the average micro-strip antenna, it can be used to transmit and receive antennas [13-16].

Table 1 provides the parameters of the study and the literature $[1-4,8]$ antennas. It is not hard to find that our research in antenna has obvious advantages in bandwidth, gain and antenna size compared to the literature [1-4,8] antennas, which demonstrates that a coplanar waveguide technology and defected ground structure can effectively widen impedance bandwidth of the antenna.

\section{The Manufactured Antenna}

In order to prove the practicality and effectiveness of the designed antenna, the size of the antenna parameters was optimized with HFSS. The optimized sizes are: $\mathrm{W}=50$ $\mathrm{mm}, \mathrm{W} 1=2.6 \mathrm{~mm}, \mathrm{~L}=40 \mathrm{~mm}, \mathrm{~L} 1=25 \mathrm{~mm}, \mathrm{~S}=0.28$ $\mathrm{mm}, \mathrm{a}=42 \mathrm{~mm}, \mathrm{~b}=8.2 \mathrm{~mm}, \mathrm{~g}=0.8 \mathrm{~mm}$. According to the optimized size of the antenna, the antenna was actually processed and tested. Reflection coefficient S11 was measured on a vector network analyzer AV3620 and the power meter [17-18]. The antenna physical map and the reflection coefficient of the test are shown in Figure 6, radiation pattern and gain graphs of the antenna are shown in Figure 5.

Figure 6(b) reveals the simulated and measured S11 and the results track fairly well. The error of the SMA connector and the actually processing is within the allowable range.
As can be seen from Figures 5(a) and (b) the radiation pattern of measured antenna has some deviation in the high frequency, as can be seen from the diagram (c), the deviation of the measured and the simulation gain curves is mainly due to machining errors and measurement errors.

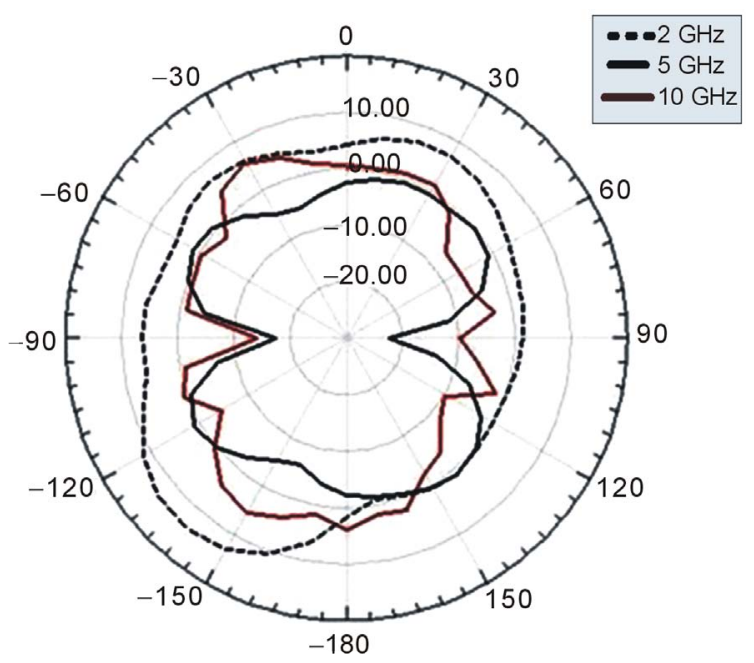

(a)

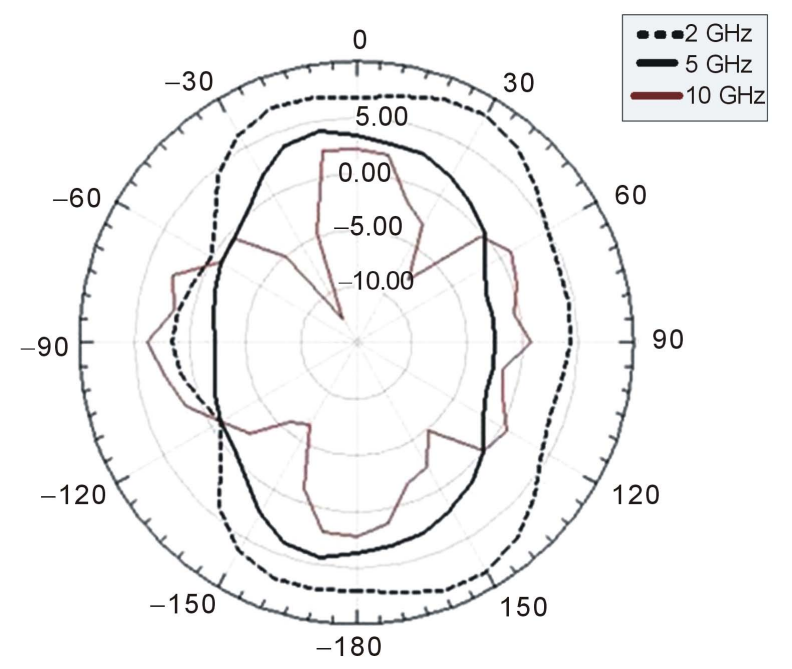

(b)

Figure 4. Radiation pattern graphs of the antenna. (a) H-plane; (b) E-plane.

Table 1. Parameters comparison of the antennas.

\begin{tabular}{ccccccc}
\hline Parameters & The paper & 4 & 5 & 6 & 7 & 8 \\
\hline Bandwidth/GHz & $2.7-9.3$ & $3.5-11.0$ & $2.8-12.3$ & $3.1-10.6$ & $3.4-11.2$ & $3.2-11.0$ \\
Relative bandwidth & 110 & 103 & 125 & 103 & 107 & 109 \\
Maximum size/mm & 50 & 28 & 44 & 50 & 30 & 18 \\
Maximum gain/dB & 8.2 & 4.50 & 5.00 & 4.00 & 5.8 & 4.80 \\
\hline
\end{tabular}




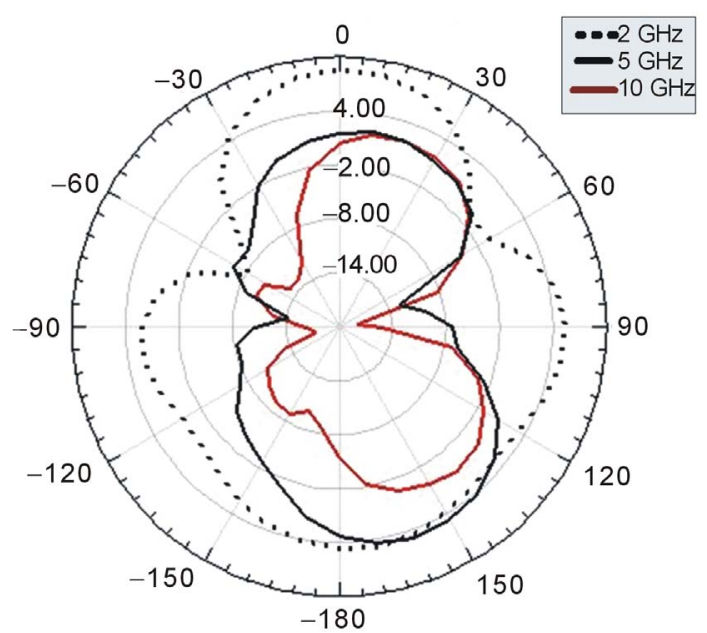

(a)

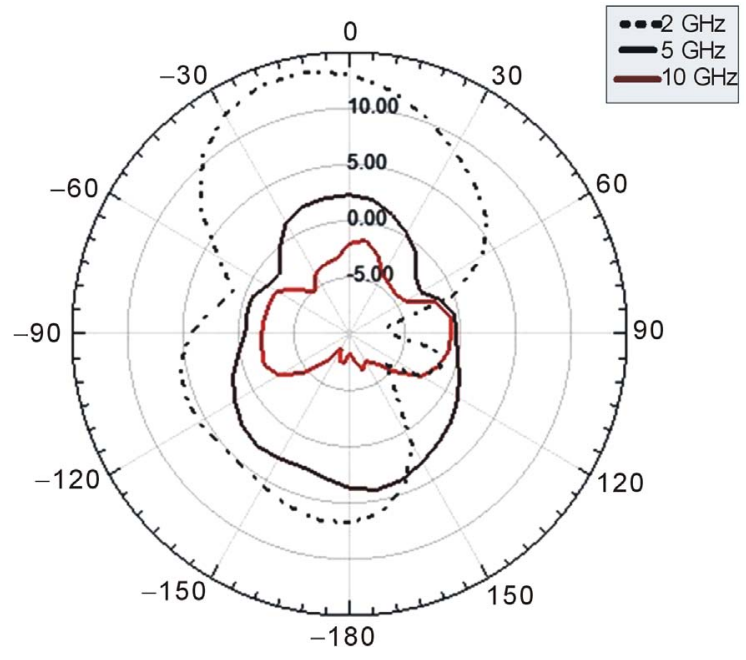

(b)

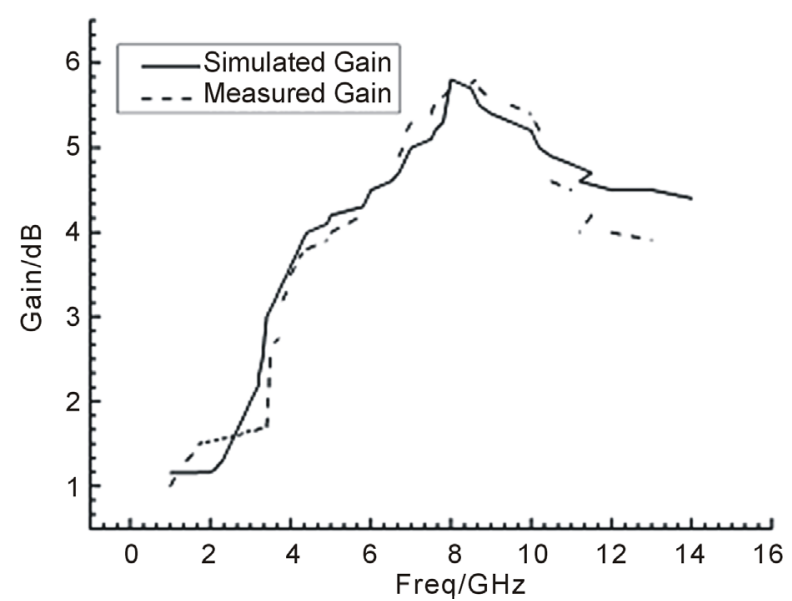

(c)

Figure 5. Radiation pattern and gain graphs of the measured antenna. (a) H-plane; (b) E-plane; (c) Gain.

\section{Conclusions}

The design of a low profile CPW-fed printed UWB an-



(a)



(b)

Figure 6. The manufactured antenna (a) and the measured return loss (b).

tenna has been proposed. The ground plane, serving as an impedance matching circuit, tunes the input impedance. The fabricated antenna is compact with dimensions of 40 $\times 50 \times 1.6 \mathrm{~mm}^{3}$ suitable for integration with electrical circuits.

Both simulation and measurement have demonstrated that the trapezoidal CPW-fed printed antenna can achieve an ultra wide bandwidth. It is also observed that the radiation patterns are nearly Omnidirectional over the entire operating bandwidth. The results have proved that the design stands out as a potential candidate for future UWB applications.

\section{Acknowledgements}

The authors would like to thank Mr. Fang Anan of the Department of Electronic, Nanchang University for his help in the fabrication and measurement of the antenna. The authors would like to acknowledge the financial support provided by he National Science Funds of China (No.61062009), Key Technology R\&D Program of Jiangxi (No. 2009BGB02200), Science and Technology 
Foundation of Department of Transportation in Jiangxi province (2010H0017).

\section{REFERENCES}

[1] W. Zhou, Y. S. Li and C. Y. Liu, "Research on a CPWFed Ultra-Wideband Antenna,” Microwaves, Vol. 26, No. 8, 2010, pp. 234-237.

[2] Y. J. Ren and K. Chang, "An Annual Ring Antenna for UWB Communications,” IEEE Antennas Wireless Propagation Letters, Vol. 5, No. 1, 2006, pp. 274-276. http://dx.doi.org/10.1109/LAWP.2006.875897

[3] C. Zhou, H. L. Cao and L. S. Yang, "An Improved Coplanar Waveguide-Fed Ultra-Wideband Antenna Design,” Chongqing University of Posts and Telecommunications (Natural Science), Vol. 20, No. 1, 2008, pp. 39-41.

[4] Y. Q. Wu, S. W. Hu, K. M. Liao, H. L. Zhou and M. Tang, “An Improved U-shaped Slot Ultra-Wideband Microstrip Antenna,” Electronic Components and Materials, Vol. 09, 2012, pp. 55-58.

[5] W.-J. Lu, Y. Cheng and H.-B. Zhu, "Design Concept of a Novel Balanced Ultra-Wideband (UWB) Antenna,” 2010 IEEE International Conference on Ultra-Wideband (ICUWB), Vol. 20, No. 23, 2011, pp. 1-4.

[6] A. Subbarao and S. Raghavan, “A Novel Pot Shaped CPW-Fed Slot Antenna for Ultra Wideband Applications,” Emerging Trends in Electrical and Computer Technology, Vol. 23, No. 24, 2011, pp. 1119-1122.

[7] Y. Z. Shen and Law Choi Look, "A Microstrip-Fed Quasi-Spiral Circularly Polarized Ultra-Wideband Antenna,” 2011 IEEE International Symposium on Antennas and Propagation, Vol. 20, No. 23, 2011, pp. 1-4. http://dx.doi.org/10.1109/APS.2011.5996570

[8] S. J. Shi and H. P. Guo, “A New Type of Ultra-Wideband Planar Monopole Antenna Design,” Communication Technology, Vol. 42, No. 1, 2009, pp. 112-114.

[9] Y. S. Jia, I. G. Chung and W. C. Zhi, "Broadband CPWFed Circularly Polarized Square Slot Antenna with Lightening-Shaped Feedline and Inverted-L Grounded Strips,” IEEE Transactions on Antennas and Propagation, Vol. 3, No. 58, 2010, pp. 973-977. http://dx.doi.org/10.1109/TAP.2009.2039335

[10] M. A. Habib, A. Bostani and A. Djaiz, "Ultra Wideband
CPW-Fed Aperture Antenna with WLAN Band Rejection,” Progress in Electromagnetics Research, Vol. 106, 2010, pp. 17-31. http://dx.doi.org/10.2528/PIER10011905

[11] M. S. Yuan and Y. L. Chung, "CPW-Fed Dual Folded Symmetry Planar Antenna for Multiband Operation,” International Conference on Electromagnetics, Applications and Student Innovation (iWEM), Taipei, 2011, pp. 43-47.

[12] P. Pongsoon and D. Bunnjaweht, "CPW-Fed Disc Patch Antennas with an Annular Ground Plane for UWB Applications," International Symposium on Intelligent Signal Processing and Communications Systems (ISPACS), Chiang Mai, 2011, pp.1-4. http://dx.doi.org/10.1109/ISPACS.2011.6146217

[13] J. X. Huang, F. S. Zhang and Q. Zhang, "Novel WideSlot Antenna Fed by Equiangular Spiral for Ultra-Wideband Communications," Processing IEEE International Conference on Ultra-Wideband (ICUWB), 2010, Vol. 1, pp. 1-3.

[14] S. Shrestha, J.-J. Park, S.-K. Noh and D.-Y. Choi, "Design of $2.45 \mathrm{GHz}$ Sierpinski Fractal Based Miniaturized Microstrip Patch Antenna," 18th Asia-Pacific Conference on Communications (APCC), 15-17 October 2012, pp. 36-41.

[15] D. Nashaat, H. A. Elsadek, E. A. Abdallah, M. F. Iskander and H. M. Elhenawy, "Ultrawide Bandwidth $2 \times 2$ Microstrip Patch Array Antenna Using Electromagnetic Band-Gap Structure (EBG)," IEEE Transactions on Antennas and Propagation, Vol. 59, No. 5, 2011, pp. 15281534.

[16] R. J. Chitra and V. Nagarajan, "Design of Double U-Slot Microstrip Patch Antenna Array for WiMAX," 2012 International Conference on Green Technologies (ICGT), 18-20 December 2012, pp. 130-134.

[17] M.-P. Jin, M.-Q. Qi and W. Wang, “A Conformal Microstrip Patch Antenna Array,” 2011 3rd International AsiaPacific Conference on Synthetic Aperture Radar (APSAR), 26-30 September 2011, pp. 1-2.

[18] F. Zhang, F.-S. Zhang, Y.-B. Yang and Z. Zhang, "Wide Band Antenna Array Using Bowtie-Shaped Microstrip Patch Antenna," 2010 International Conference on Microwave and Millimeter Wave Technology (ICMMT), 8-11 May 2010, pp. 424-427. 